\title{
Role of thoracoscopic pleural biopsy in evaluation of pleural effusion
}

\author{
Tameem Afroz ${ }^{1, *}$, Sistla Radha ${ }^{2}$ \\ ${ }^{1}$ Consultant, ${ }^{2}$ Consultant and HOD, Dept. of Anatomical Pathology and Cytology, Aware Gleneagles Global Hospitals, \\ Hyderabad, Telangana, India
}

*Corresponding Author: Tameem Afroz

Email: tameemafroz@hotmail.com

Received: $19^{\text {th }}$ February, 2018

Accepted: $19^{\text {th }}$ April, 2018

\begin{abstract}
Context: Evaluation of a patient with pleural effusion involves clinical, radiological and cytological evaluation of pleural fluid and histological evaluation of pleural biopsy. It is not always possible to identify the exact etiology of pleural effusion based on cytological examination alone. Pleural biopsy is sensitive in up to $91 \%$ of cases.

Aims: The Aim of the paper is to study the diagnostic yield of thoracoscopic pleural biopsy and to ascertain the etiology of pleural effusions.

Materials and Methods: The material for this study is pleural biopsies received in the department of pathology in a tertiary care hospital. A total of 103 biopsies were studied in three years (2013-2015). Biopsies were fixed in buffered formalin and routinely processed. A panel of histochemical stains and immuno histochemical markers were done when required.

Statistical Analysis used: None

Results: A total of 103 biopsies were studied. M: F ratio is 2.1:1. Youngest patient was 16 years and oldest was 80 years. Most common diagnosis was tuberculosis, diagnosed in 32 cases $(32.6 \%)$, other lesions diagnosed were acute infection 10 cases $(10.2 \%)$, chronic inflammation 24 cases $(24.5 \%)$, adenocarcinoma $13(13.2 \%)$, squamous cell carcinoma 5 (5.1), lymphoma 5 (5.1\%), mesothelioma four cases $(4.08 \%)$, one each of small cell carcinoma, poorly differentiated carcinoma, solitary fibrous tumour, xanthogranulomatous inflammation, extra medullary hematopoiesis, benign mesothelial hyperplasia constituting (1.0\%) each. Four biopsies were inadequate and excluded from the study.

Conclusions: Thoracoscopic pleural biopsy has a very high sensitivity $91 \%$ and a specificity of $100 \%$ in diagnosing pleural effusions. It is a safe procedure. Material obtained can be used for ancillary techniques in cases of diagnostic dilemmas.
\end{abstract}

Keywords: Pleural effusion, Pleural Biopsy, Thoracoscopy.

Key Messages: Pleural biopsy evaluation is a useful modality in diagnosing pleural effusions.

\section{Introduction}

Pleural diseases are common problems in pulmonary medicine. A variety of benign and malignant diseases cause pleural effusion. It is not always possible to diagnose the underlying cause of pleural effusion by clinical, radiological or cytological examination. The diagnostic yield of cytology is $60 \% .^{1}$ Such cases usually require pleural biopsy for definite diagnosis. Pleural biopsies have a sensitivity of $91 \%$ and specificity of $100 \% .^{2}$ It is a safe and reliable procedure with fewer complications. This study is undertaken to determine the etiology of pleural effusions to facilitate better management of patients. Results obtained varied from common inflammatory lesions to rare lesions like solitary fibrous tumour, xanthogranulomatous pleuritis and extra medullary hematopoiesis. Pleural biopsies have a definite role in the diagnosis of pleural diseases which cannot be diagnosed by other modalities.

\section{Materials and Methods}

This is a prospective study carried out in the department of pathology in a tertiary care hospital. Indication for pleural biopsy was exudative effusions. Presenting features included fever, dyspnoea and pain. Thoracoscopy was done after clinical evaluation of the patient with an $11 \mathrm{~mm}$ rigid thoracoscope. Respiratory status was evaluated in every case before the procedure. After explaining the procedure to the patient, he/she is put in a lateral position with the healthy side down. The procedure is done under local anaesthesia. An axillary portal of entry is selected in most cases at the level of $4^{\text {th }}$ or $5^{\text {th }}$ intercostal space. After visualizing the cavity and identifying the abnormal areas, biopsies are taken from those areas. The patient is observed for $24 \mathrm{hrs}$ and discharged. A total of 103 biopsies were studied over a period of three years from 2013-15. There were four inadequate biopsies which did not show any pleural tissue which were excluded from the study. Tissue was fixed in buffered formalin and processed routinely. Haematoxylin and Eosin (H\&E) stained sections were examined by two pathologists. Histochemical stains like AFB fungal stains were done where required.

Immunohistochemical markers were used to definitely type lesions. The markers used are CD45, pancytokeratin, CK7, CK20, synaptophysin, CD34, TTF, BCL2, CD68, calretinin and lymphoma panel markers. 


\section{Results}

Normal pleural tissue has a visceral and parietal compartment, sub mesothelial screen compartment and sub mesothelial adipose tissue compartment. A pleural biopsy is considered adequate when two of the three compartments are present in the ratio of $3: 1$. Histological patterns of lesions identified were classified as granulomatous, nonspecific inflammatory, purulent and neoplastic. Total of 103 biopsies were studied out of which 4 were inadequate. The details of inflammatory lesions is given in Table 1 .

Pyogenic inflammation revealed groups and sheets of neutrophils associated with areas of necrosis and nuclear debris. Chronic nonspecific pleuritis was characterized by fibrin deposits in sub pleural area with discrete chronic inflammatory cell infiltration. There was reactive fibroblastic proliferation.

Granulomatous lesions were composed of fibrin with granulation tissue and granulomas. These were composed of epithelioid cells and langhans giant cells. There were areas of necrosis in 28 cases and in 4 cases they were non caseating. Stains for AFB were positive in only 7 cases. PCR -TB was positive in 16 cases. Culture was positive in five cases.

Xanthogranulomatous lesion had inflammatory infiltrate composed of lymphocytes, plasma cells and few neutrophils. Sheets and groups of foam cells were seen. [Fig. 2A] There was focal giant cell reaction. Stains for AFB and Fungus were negative. These cells were Epithelial Membrane Antigen (EMA), HMB- 45 negative and were CD68 positive. [Fig. 2B]

There were 30 malignant lesions. Details of various lesions are given in Table 2.

There were 13 adenocarcinomas, nine were deposits from lung carcinoma, [Fig. 1A] three were metastasis from gastrointestinal malignancy [Fig. 1C] and one was a deposit from ovarian carcinoma. A definite diagnosis was made using IHC markers.

There were four cases of mesotheliomas. [Fig. 1D] Only one was a biphasic variant. Other lesions were monophasic with glandular pattern. These lesions were differentiated from adenocarcinomas by using Calretinin and TTF. [Fig. 1B]

There were five cases of squamous cell carcinoma, two were well differentiated and three were moderately differentiated. Out of the five cases, four were metastatic deposits from lung carcinoma and was a metastatic deposit in a diagnosed case of squamous cell carcinoma cervix.

There were five cases of lymphoma. Three were diffuse large B cell lymphomas. [Fig. 3C\&3D] Two cases were not investigated further.

One case of poorly differentiated malignancy was diagnosed. IHC was advised but patient was lost to follow up.

One case showed spindle cells in bundles and fascicles. [Fig. 3A] Nuclei had clumped chromatin and mitoses were sparse. Cells were diffusely and strongly positive for CD 34 positive. [Fig. 3B] and a diagnosis of solitary fibrous tumour of pleura was offered.

In one case of recurrent pleural effusion, pleural biopsy revealed myeloid elements some of which were immature and there was an occasional megakaryocyte. [Fig. 2C\&2D] The lesion was diagnosed as extra medullary haematopoiesis. Further evaluation revealed multiple myeloma. Patient is under follow up with a clinical hematologist.

In one biopsy, there was reactive mesothelial hyperplasia. Mesothelial lining was thrown into folds. There was increase in cellularity, mitoses were absent. These findings were associated with dense chronic inflammation. The patient was diagnosed to have rheumatoid arthritis. Clinical and pathological details of these lesions in given in table 3.

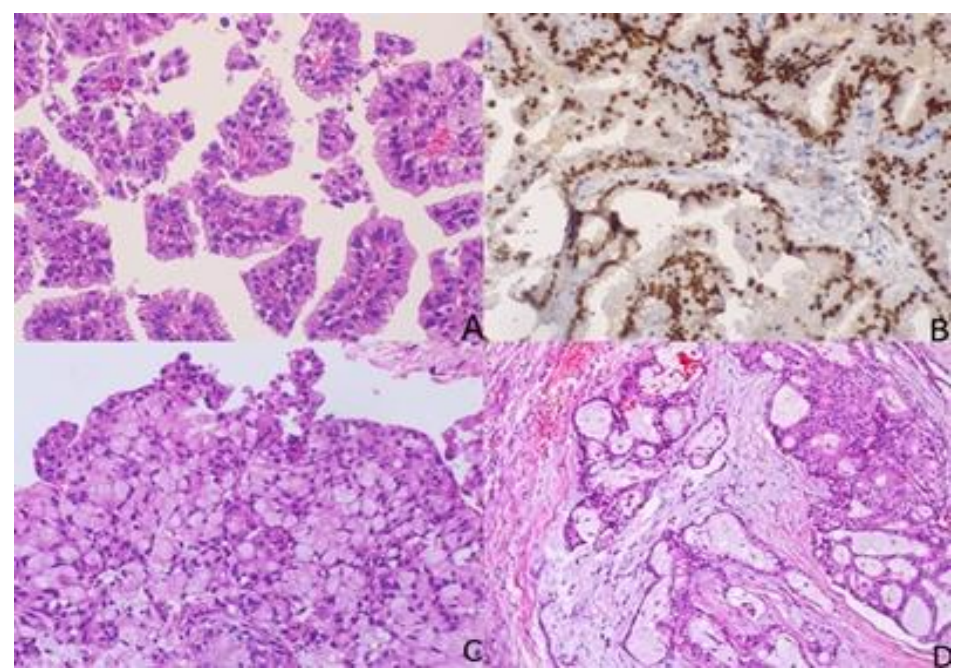

Fig. 1: 1A Section showing papillary adenocarcinoma.(H\&EX200); B: Papillary adenocarcinoma showing diffuse strong TTF-1 positivity(X200); C: Sections showing metastatic deposits of signet ring cell carcinoma. (H\&EX200); D: Sections showing glandular variant of mesothelioma.(H\&EX200) 


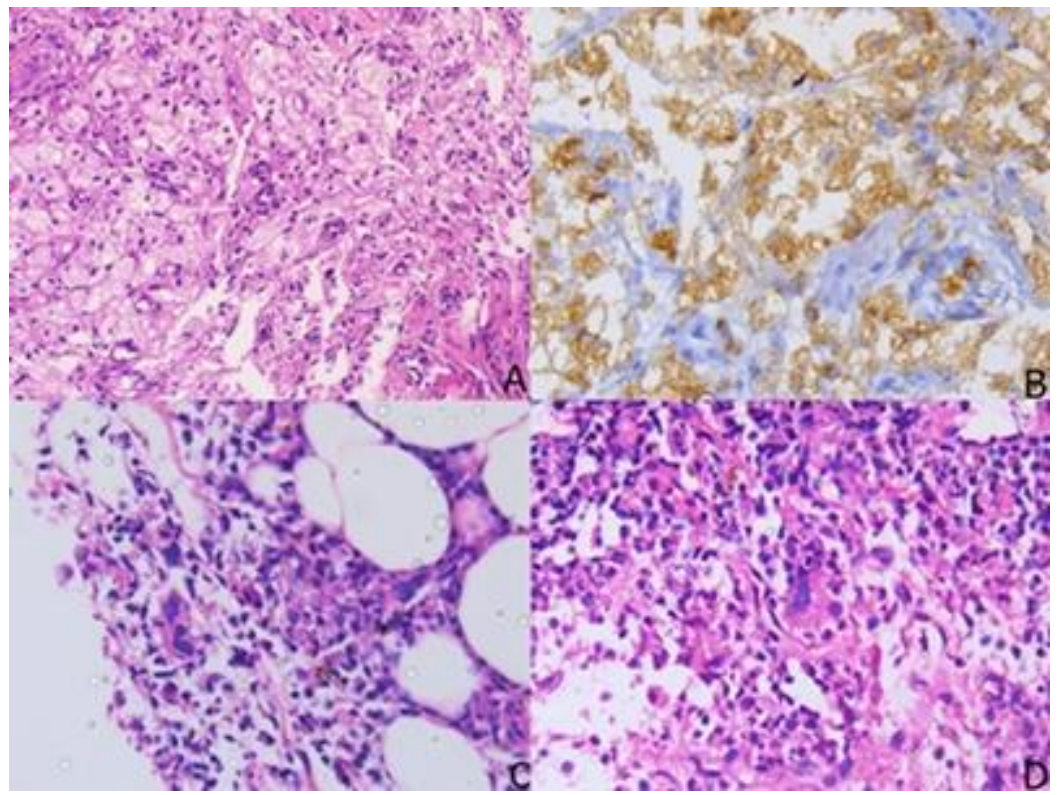

Fig. 2: 2A; Sections showing xanthogranulomatous inflammation with sheets of foam cells.(H\&EX200); 2B: Sections showing foam cells which are CD68 positive.(x400); 2C: Sections showing pleural tissue with marrow elements.(H\&EX100); 2D: Sections showing marrow elements with megakaryocytes.(H\&EX200)

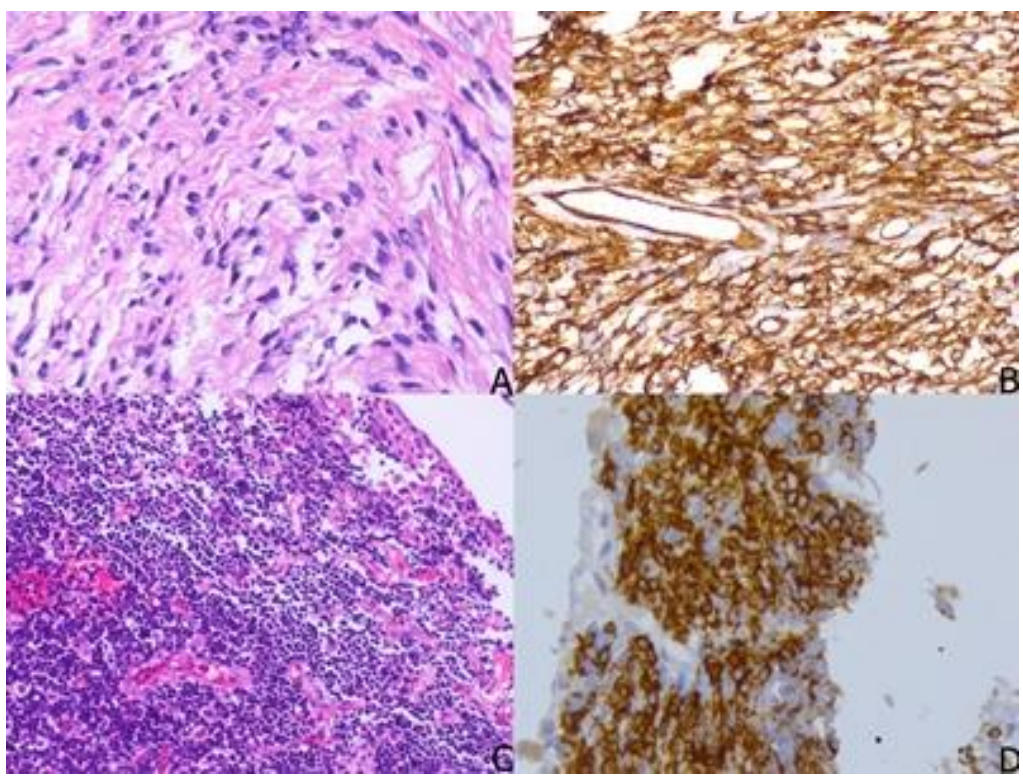

Fig. 3: 3A Sections showing interlacing bundles of spindle cells with mildanisonucleosis. (H\&EX200); B: Sections showing strong CD34 positivity in solitary fibrous tumour. (X200); C: Sections showing pleural tissue with atypical lymphoid infiltrate.(H\&EX100); D: Sections showing diffuse strong CD20 positivity.(X100)

Table 1: Inflammatory lesions

\begin{tabular}{|l|c|c|c|c|c|c|}
\hline S. No & Diagnosis & No of cases & Percentage & Age & M:F & Ancillary \\
\hline 1 & Pyogenic inflammation & 10 & $10.2 \%$ & $17-64$ & $4: 1$ & Culture \\
\hline 2 & $\begin{array}{c}\text { Chronic nonspecific } \\
\text { inflammation }\end{array}$ & 24 & $24.4 \%$ & $30-76$ & $5: 1$ & Serology \\
\hline 3 & $\begin{array}{c}\text { Granulomatous } \\
\text { inflammation }\end{array}$ & 32 & $32.6 \%$ & $16-78$ & $1.1: 1$ & $\begin{array}{c}\text { ZN Stain, } \\
\text { PCR TB }\end{array}$ \\
\hline 4 & $\begin{array}{c}\text { Xanthogranulomatous } \\
\text { inflammation }\end{array}$ & 1 & $1 \%$ & 45 & M & $\begin{array}{c}\text { CD68, } \\
\text { Fungal and ZN stains }\end{array}$ \\
\hline
\end{tabular}


Table 2: Malignant lesions

\begin{tabular}{|c|c|c|c|c|c|}
\hline S. No & Type of malignancy & $\begin{array}{c}\text { Age Range } \\
\text { (years) }\end{array}$ & M:F & No and \% of cases & $\begin{array}{l}\text { Ancillary } \\
\text { Methods }\end{array}$ \\
\hline 1 & $\begin{array}{l}\text { Mets of adeno carcinoma } \\
\text { lung }\end{array}$ & $33-82$ & $2: 1$ & $\begin{array}{c}9 \\
9.1 \%\end{array}$ & $\begin{array}{c}\text { TTF+ } \\
\text { calretinin -ve }\end{array}$ \\
\hline 2 & Mets of GI carcinoma & $53-72$ & $1.1: 1$ & $\begin{array}{c}3 \\
3.06 \%\end{array}$ & $\begin{array}{l}\text { TTF-ve } \\
\text { CK 20+ }\end{array}$ \\
\hline 3 & Mets of ovarian carcinoma & 67 & $\mathrm{~F}$ & $\begin{array}{c}1 \\
1.02 \%\end{array}$ & $\begin{array}{c}\text { CK20/CK-7+, } \\
\text { TTF-ve }\end{array}$ \\
\hline 4 & SQCC & $51-65$ & $1: 1.1$ & $\begin{array}{c}5 \\
5.1 \%\end{array}$ & $\mathrm{CK}-7+$ \\
\hline 5 & $\begin{array}{l}\text { Small cell carcinoma } \\
\text { deposits }\end{array}$ & 60 & $\mathrm{M}$ & $\begin{array}{c}1 . \\
1.02 \%\end{array}$ & Synaptophysin + \\
\hline 6 & $\begin{array}{l}\text { Poorly differentiated } \\
\text { carcinoma }\end{array}$ & 47 & $\mathrm{~F}$ & $\begin{array}{c}1 \\
1.02 \%\end{array}$ & - \\
\hline 7 & Mesothelioma & $37-60$ & $1: 1$ & $\begin{array}{c}4 \\
4.08 \% \\
\end{array}$ & $\begin{array}{c}\text { Calretinin } \\
+, \mathrm{TTF}-\mathrm{ve}, \mathrm{BCL} 2+\end{array}$ \\
\hline 8 & Lymphoma & $14-65$ & $1: 4$ & $\begin{array}{c}5 \\
5.1 \%\end{array}$ & CD45 and CD 20+ \\
\hline
\end{tabular}

Table 3: Miscellaneous lesions

\begin{tabular}{|l|c|c|c|c|c|}
\hline S. No & Type of lesion & Age & Gender & No \&\% of cases & Ancillary methods \\
\hline 1. & Solitary fibrous tumour & 65 & $\mathrm{M}$ & $1-1.02 \%$ & CD-34+ \\
\hline 2. & $\begin{array}{c}\text { Nodular mesothelial } \\
\text { hyperplasia }\end{array}$ & 55 & $\mathrm{~F}$ & $1-1.02 \%$ & Serology, RA+ \\
\hline 3. & $\begin{array}{c}\text { Extra medullary } \\
\text { haematopoiesis }\end{array}$ & 68 & $\mathrm{M}$ & $1-1.02 \%$ & $\begin{array}{c}\text { Bone marrow and } \\
\text { electrophoresis }\end{array}$ \\
\hline
\end{tabular}

\section{Discussion}

Pleural disease can involve visceral or parietal pleura in the form of inflammatory or neoplastic disorders. This results in pleural effusions. Evaluation of pleural effusion includes cytological analysis, microbiological and biochemical analysis. Approximately $40 \%$ of pleural effusions remain undiagnosed. Pleural biopsy can increase the diagnostic yield further and decreases the number of undiagnosed cases. Pleural tissue can be obtained by various methods. In our institute, pleural biopsy is done by thoracoscopic method. This procedure facilitates viewing the pleural surface and identifying the abnormal areas and taking multiple biopsies. Thoracoscopy is a safe procedure with minor reversible complications like pain and hypoxemia. Mortality is very rare and is $0.01 \%$.

Indications for pleural biopsies are pleural effusion of unknown etiology and pleural thickening. In this study, the main indication was exudative pleural effusion of undiagnosed etiology.

Granulomatous inflammation was the commonest non neoplastic lesion in our study constituting $32.6 \%$ of cases. Other studies in literature also reported granulomatous inflammation as the commonest lesion. ${ }^{3}$ A definite diagnosis of tuberculosis can be made if mycobacterium tuberculosis is identified in pleural specimens. In pleural fluid, identification of AFB is an uncommon occurrence. In one study, positivity was reported in $10 \%$ of cases. ${ }^{4}$ Culture of pleural biopsy is helpful and is positive in $85 \%$ of cases. In our study, material for culture was available in 5 cases and in all the cases culture was positive. In 19 cases, PCR for tuberculosis was done and was useful in 16 cases. After performing AFB stains, culture and molecular methods, four cases of granulomatous inflammation remain undiagnosed.

The second most common pattern was chronic nonspecific pleuritis. This is diagnosed using specific criteria. ${ }^{5}$ Features include fibrin deposition in the sub pleural compartment and discrete signs of chronic inflammation. Fibrous tissue shows reactive changes. The causes of nonspecific pleuritis are chronic renal failure, vasculitis, pancreatitis, congestive cardiac failure, tuberculosis and para neoplastic pleuritis. It is important to correlate clinical, serological, biochemical findings and decrease the diagnosis of nonspecific pleuritis. Thoracoscopic pleural biopsy increases the diagnostic yield in patients with benign and malignant pleural disease. ${ }^{6}$

The commonest malignant lesion in this study was adenocarcinoma constituting 13.2\%. Pleural metastasis is more common than primary neoplasm. The most common neoplasms metastasising to pleura are from lung. ${ }^{7}$ In our study also the most common type of adenocarcinoma was metastasis from primary lung adenocarcinoma. There is a large histological overlap of various adenocarcinomas and it is not always possible 
to definitely type the lesions. Clinical, radiological correlation and ancillary methods on tissue like immune stains and molecular methods in some cases should be done for a definite diagnosis.

Solitary fibrous tumour of pleura is rare. Majority of SFT in pleura are benign. It is a rare neoplasm and approximately 800 cases are reported in literature showing the rarity of the lesion. ${ }^{8}$ England et al suggested that solitary fibrous tumour originates from mesothelial connective tissue and suggested that primitive multipotential mesenchymal cell as cell of origin. Criteria for malignancy are increased cellularity, high mitotic rate, pleomorphism and necrosis. ${ }^{9}$

Extra medullary haematopoiesis (EMH) is a compensatory mechanism that occurs when bone marrow is unable to maintain sufficient production to supply body demands. EMH is common in reticuloendothelial organs like spleen, liver and lymph nodes. EMH is reported in a variety of sites like mediastinum, breast, central nervous system, peripheral nerves, orbit, middle ear, pancreas, urethra, pericardium, heart, lungs and pleura, gastro intestinal tract, thyroid, skin, kidney, adrenal, prostate, ovaries and endometrium. ${ }^{10}$

Thoracic EMH is seen as 1) Heterotopia 2) Hyperplasia of marrow from the rib. These cases are associated with various haematological abnormalities like myelofibrosis, hemoglobinopathies and other chronic haemolytic anaemias. In a small percentage of cases these can be reactive without any obvious hematological abnormality. In our case, it was associated with multiple myeloma. Association of EMH is more common with anaemias and is rare with multiple myeloma. Baladane et al reported pulmonary EMH mimicking plasmacytoma in a patient with multiple myeloma. ${ }^{11}$

We reported five cases of lymphoma. Two cases were diagnosed as diffuse large B cell lymphomas. They were secondary pleural involvement. One case had no other lesion hence diagnosed as primary pleural lymphoma. The others were lost to follow up and further investigations. Pleural involvement in NHL is seen in up to $20 \%$ of cases. Primary pleural involvement is extremely rare and reported in $<4 \%$ of cases. It can be unilateral or bilateral. Pleural effusion with pleural involvement is a poor prognostic factor. In a large study of 34 cases of lymphoma of pleura the commonest sub type was diffuse large B cell lymphoma. The other types reported are histiocyte rich large B cell lymphoma, follicular lymphoma, small lymphocytic lymphoma, mantle cell lymphoma and classical Hodgkin's lymphoma. ${ }^{12}$

One case of benign mesothelial proliferation was reported. There are various causes of mesothelial proliferation like collagen vascular disease, drug reactions and trauma. Our case was a diagnosed as rheumatoid arthritis on further evaluation. Features like high cellularity, mitoses can mimic malignancy.
Sometimes a false diagnosis of malignancy can be made by benign mimics like entrapment or en face cuts of poorly oriented tissue. ${ }^{13}$

One case was diagnosed as xanthogranulomatous lesion. Differential diagnosis of clear cell tumours was considered. Cells were EMA and HMB45 negative and CD 68 positive.

\section{Conclusions}

Thoracoscopic pleural biopsy is a safe procedure with very few complications. The sensitivity and specificity of diagnosis is high on pleural biopsies when compared to cytological evaluation alone. Tissue is available for ancillary studies. The diagnosis of nonspecific pleuritis can be reduced in correlation with other investigations.

\section{References}

1. Hooper C, Lee YC, Maskell N. Investigation of unilateral pleural effusion in adults: British Thoracic Society Pleural Disease Guideline 2010. Thorax. 2010;65:214-17.

2. Agarwal R, Aggarwal AN, Gupta D. Diagnostic accuracy and safety of semi rigid thoracoscopy in exudative pleural effusions: a meta-analysis. Chest. 2013;144:1857-67.

3. Rama Saha, Pamela Nayak, Aruna Bhattacharya, Santanu Dutta. The study of pleural diseases with special reference to cytopathology and histopathology. International Journal of Biomedical and Advance Research. 2015;6:599-610.

4. Abumossalam AM, Moawd AA, Shebl AM. Assessment of histopathological prototypes of the pleural fluid and granulomatous tissue reaction associated with pleural tuberculosis. Egyptian Journal of Chest Diseases and Tuberculosis. 2014;63:907-11.

5. Vera Luiza Capelozzi, Paulo Hilario N Saldiva, Leila Antonangelo, Teoclito Sachetto de Carvalho, Angela Logulo et al.Quantitation in inflammatory pleural disease to distinguish tuberculous and paramalignant from chronic non specific pleuritic. J Clin Pathol. 1997;50:935-40.

6. Mohamed SA, Shaban MM. Diagnostic yield of medical thoracoscopy in diagnosis of exudative pleural effusion: One year prospective study. Egyptian Journal of Chest Disease and Tuberculosis. 2014;63:897-905.

7. Lalitkumar V LAD, Ahmed Toha Samsudin, Kunji Kannan, Jaafar Sadeq Makki, Moharzudi Mohamed. Diagnostic flex-rigid bronchoscopic biopsy of pleura for exudative pleural effusions in suspected malignant and tuberculosis cases: a retrospective study of 219 cases. Malaysian J Pathol. 2015;37:101-7.

8. De Perrot M, Fischer S, Brundler MA, Sekine Y, Keshavjee S. Solitary fibrous tumors of the pleura. Ann Thorac Surg 2002;74:285-93.

9. England DM, Hochholzer L, Mc Carthy MJ. Localised benign and malignant fibrous tumours of the pleura: a clinic pathologic review of 223 cases. Am J Surg Pathol. 1989;13:640-58.

10. Koch CA, Li CY, Mesa RA, Tefferi A. Nonhepatosplenic extramedullary hematopoiesis: associated diseases, pathology, clinical course and treatment. Mayo Clinic Proc. 2003;78:1223-33.

11. Baldane S, Sivgin S, Kaynar L, Ozaslan E, Yildririm A, $\mathrm{Canoz} \mathrm{O}$ et al. Pulmonary extramedullary hematopoiesis mimicking plasmacytoma in a patient with multiple myeloma. Rom J Intern Med. 2015;53:353-8. 
12. Ahmed H, Pawade J, Falk S, Morgan JA,

Balacumaraswami L.Primary pleural lymphomas. Thorax. 2003;58:908-9.

13. Cagle PT, Churg A. Differential diagnosis of benign and malignant mesothelial proliferations on pleural biopsies. Arch Pathol Lab Med. 2005;129:1421-27.

How to cite this article: Afroz $\mathrm{T}$, Radha $\mathrm{S}$. Role of thoracoscopic pleural biopsy in evaluation of pleural effusion. Indian J Pathol Oncol. 2018;5(4):518-523. 